\title{
Grain size effect on self-mated CVD diamond dry tribosystems
}

\author{
C.S. Abreu ${ }^{\text {a }}$, F.J. Oliveira ${ }^{\mathrm{b}}$, M. Belmonte ${ }^{\mathrm{c}}$, A.J.S. Fernandes ${ }^{\mathrm{d}}$, R.F. Silva ${ }^{\mathrm{b}, *}$, J.R. Gomes ${ }^{\mathrm{e}}$ \\ ${ }^{a}$ Physics Department, Porto Superior Engineering Institute, ISEP, 4200-072 Porto, Portugal \\ ${ }^{\mathrm{b}}$ Ceramics Engineering Department, CICECO, University of Aveiro, 3810-193 Aveiro, Portugal \\ ${ }^{\mathrm{c}}$ Instituto de Cerámica y Vidrio (CSIC), Cantoblanco, 28049 Madrid, Spain \\ ${ }^{\mathrm{d}}$ Physics Department, University of Aveiro, 3810-193 Aveiro, Portugal \\ e Mechanical Engineering Department, CIICS, University of Minho, 4800-058 Guimarães, Portugal
}

Received 31 July 2004; received in revised form 30 December 2004; accepted 7 January 2005

Available online 3 February 2005

\begin{abstract}
Chemical vapour deposited (CVD) diamond coatings are important for tribological applications due to their unique combination of properties. Previous work demonstrated that silicon nitride $\left(\mathrm{Si}_{3} \mathrm{~N}_{4}\right)$ excels as a substrate for diamond coatings due to its low thermal expansion coefficient mismatch relative to diamond films resulting in a significant adhesion improvement. In this study, dense $\mathrm{Si}_{3} \mathrm{~N}_{4}$ substrates were fabricated by pressureless sintering and diamond coated by microwave plasma chemical vapour deposition (MPCVD). The deposition time varied between 1 and $10 \mathrm{~h}$ in order to investigate the effect of the diamond grain size and film thickness on the tribological behaviour of self-mated CVD diamond coatings on $\mathrm{Si}_{3} \mathrm{~N}_{4}$. Reciprocating dry sliding ball-on-flat (BOF) wear tests were performed in air up to $16 \mathrm{~h}$, at room temperature, with normal applied load ranging from 10 to $105 \mathrm{~N}$. The stroke and frequency of the sliding motion were kept constant with values of 6 mm and $1 \mathrm{~Hz}$, respectively. Several characterisation techniques (scanning electron microscope (SEM), atomic force microscope (AFM), microRaman) were used to identify the prevailing surface damage mechanisms. After a very short running-in regime, with high friction coefficients, a steady-state regime is reached, characterized by extremely low friction values $(\mu \sim 0.03)$. A mild wear mode was achieved for the longer runs, with wear coefficient values around $10^{-8} \mathrm{~mm}^{3} \mathrm{~N}^{-1} \mathrm{~m}^{-1}$. The larger grain sized and thicker coatings present smaller compressive residual stresses (below $1 \mathrm{GPa}$ ) due to a better in-depth accommodation of the contact pressure. This delays film delamination to much higher applied loads $(105 \mathrm{~N})$ than the thinner, small grain sized coatings, grown for $1 \mathrm{~h}$ that fail in sliding under $35 \mathrm{~N}$ of normal load.
\end{abstract}

(C) 2005 Elsevier B.V. All rights reserved.

Keywords: Wear; Friction; CVD diamond; Grain size

\section{Introduction}

Diamond coating films can improve many surface properties of engineering substrate materials, including erosion, corrosion and wear resistance. Moreover, cleaved diamond surfaces exhibit one of the lowest friction coefficients of any known material, making them ideal for highly demanding tribological applications in open air [1,2]. In particular, diamond films obtained by chemical vapour deposition (CVD) technique have demonstrated suitable behaviour that makes them appropriate for many technological applications where

\footnotetext{
* Corresponding author. Tel.: +35 1234 370243; fax: +35 1234425300.

E-mail address: rsilva@cv.ua.pt (R.F. Silva).
}

these characteristics are determinant. This technology has significantly lowered the cost of synthetic diamond comparing to that of the conventional high pressure-high temperature (HPHT) diamond. Thus, CVD diamonds films are used or being considered as coating material for machine cutting tools, mechanical face seals, protective coatings for aerospace components, hard disks and medical implants [3-6].

Various metallic and non-metallic substrate materials are employed for CVD diamond deposition [7]. Among them, silicon nitride $\left(\mathrm{Si}_{3} \mathrm{~N}_{4}\right)$ is gaining increasing importance due to the low thermal expansion coefficient mismatch between the diamond film and substrate. This minimises the interfacial residual stresses between the coating and substrate, leading to enhanced diamond/substrate adhe- 
sion. Further, $\mathrm{Si}_{3} \mathrm{~N}_{4}$ possesses high hardness, high fracture toughness, an excellent thermal shock resistance, low coefficient of friction in open air and excellent wear resistance $[8,9]$.

Most diamond-on-diamond tribological studies have been performed using mainly natural single-crystal diamond as the counterpart material $[1,3,10,11]$. Moreover, recent works on CVD diamond films were primarily oriented on the study of frictional properties of the coatings under vacuum conditions, under partial pressures of atmospheric gases or performed with small applied normal loads [12]. Gardos [2] performed scanning electron microscope (SEM) tribometry studies of self-mated diamond films in vacuum, or at partial pressures of hydrogen and oxygen, to examine the surface chemistry-induced friction and wear changes as a function of atmospheric environment and temperature. Miyoshi et al. [13] investigated the potential of CVD diamond-coated $\mathrm{Si}_{3} \mathrm{~N}_{4}$ substrate for solid film lubrication, among other coatings, under humid air, dry nitrogen and ultrahigh vacuum conditions. Low coefficients of friction $(<0.1)$ and moderate wear rates $\left(\leq 10^{-6} \mathrm{~mm}^{3} \mathrm{~N}^{-1} \mathrm{~m}^{-1}\right)$ were reported for the unlubricated sliding of self-mated CVD diamond films in humid air. However, such tests were performed with an applied load of only $0.98 \mathrm{~N}$. To such an extent, very limited information regarding the wear properties of self-mated CVD diamond-coated $\mathrm{Si}_{3} \mathrm{~N}_{4}$, particularly for higher applied loads, is available in the open literature.

The objective of this study is to investigate the influence of diamond grain size on the tribological performance of selfmated CVD diamond-coated $\mathrm{Si}_{3} \mathrm{~N}_{4}$ parts. Sliding tests were performed in open air using a reciprocal motion ball-on-flat (BOF) configuration in order to assess their friction and wear properties at several loads (10-105 N range). Further, the critical load prior to film delamination, originated by tribological action, was identified. SEM and AFM were used to characterize the morphology of the worn surfaces. Micro-Raman spectroscopy was used to study the quality of the deposited films and to investigate the residual stress induced by tribological action.

\section{Experimental procedure}

\subsection{Substrate material}

Substrate material consisting of dense silicon nitride $\left(\mathrm{Si}_{3} \mathrm{~N}_{4}\right)$ was prepared from starting powders of $\alpha-\mathrm{Si}_{3} \mathrm{~N}_{4}$ (Starck grade M11), $\mathrm{Y}_{2} \mathrm{O}_{3}$ (Starck grade C) and $\mathrm{Al}_{2} \mathrm{O}_{3}$ (ALCOA CT-3000SG). Batch compositions with weight proportions of $89.3,7.0$ and $3.7 \%$, respectively, were $\mathrm{Si}_{3} \mathrm{~N}_{4}$ ball milled in isopropyl alcohol during $4 \mathrm{~h}$. The obtained homogeneous suspension was then dried at $60^{\circ} \mathrm{C}$, sieved with an $115 \mu \mathrm{m}$ mesh and burnt at $400^{\circ} \mathrm{C}$ during $4 \mathrm{~h}$. In order to achieve full densification of the $\mathrm{Si}_{3} \mathrm{~N}_{4}$ substrates (>99\% of the theoretical density), the mixed powders were consolidated by uniaxial pressing at $30 \mathrm{MPa}$, followed by isostatic press- ing at $200 \mathrm{MPa}$, and then placed inside powder-bed $\mathrm{Si}_{3} \mathrm{~N}_{4} / \mathrm{BN}$ protected graphite crucibles. Flat quadrangular samples with $10 \mathrm{~mm}$ sides and thickness of $3 \mathrm{~mm}$ were finally pressureless sintered at $1750^{\circ} \mathrm{C}$ for $2 \mathrm{~h}$, under nitrogen atmosphere. Dense commercial balls of $\mathrm{Si}_{3} \mathrm{~N}_{4}$ with a diameter of $5 \mathrm{~mm}$ were also used as substrate material.

Prior to diamond deposition, all of the sintered flat samples were submitted to the following surface pre-treatment: grinding with $15 \mu \mathrm{m}$ diamond paste and subsequently polishing to a specular finishing with colloidal silica $(0.25 \mu \mathrm{m}$; type Syton). In the follow-up, the samples were manually abraded with $0.5-1 \mu \mathrm{m}$ sized diamond powder on a silk cloth and then rinsed in acetone/ethanol ultrasonic bath for $10 \mathrm{~min}$, to remove loose diamond particles. The chosen procedure for the surface pre-treatments relies on a study showing superior results, concerning diamond nucleation density and film homogeneity, for the mechanically microflawed $\mathrm{Si}_{3} \mathrm{~N}_{4}$ substrates [14]. Surface modification pre-treatments of the ball samples consisted in polishing with $0.25 \mu \mathrm{m}$ sized colloidal silica, followed by microflawing by ultrasonic agitation of diamond powder $(0.5-1 \mu \mathrm{m})$ suspension in $n$-hexane.

\subsection{Deposition technique}

Diamond deposition was carried out in a microwave plasma chemical vapour deposition (MPCVD) system (ASTeX PDS18, Seocal and Seki Technotron Corp., Japan). Different deposition conditions were used in order to achieve diamond films with distinct grain sizes and to adjust the deposition procedure to the distinct substrate geometries involved aiming similar film thicknesses in the flat and ball specimens. In the present study, three types of CVD diamondcoated $\mathrm{Si}_{3} \mathrm{~N}_{4}$ materials were tested corresponding to depositions times of $1,2.5$ and $10 \mathrm{~h}$. The deposition parameters were as follows: microwave power $=2 \mathrm{~kW}$; chamber total pressure $=1.2 \times 10^{4} \mathrm{~Pa} ; \mathrm{H}_{2} / \mathrm{CH}_{4}$ gas flow $=400 / 20$ standard cubic centimetre per minute ( $\mathrm{sccm}$ ) and $400 / 16 \mathrm{sccm}$ for the flat and ball specimens, respectively.

The diamond films in all the samples exhibited a fully adhered and continuous film aspect. A former study done by Belmonte et al. [8] in regard to the adhesion behaviour of CVD diamond-coated $\mathrm{Si}_{3} \mathrm{~N}_{4}$ produced using the same setup and similar deposition conditions (deposition time $=2 \mathrm{~h}$ ), demonstrated that the coatings did not delaminate up to an indentation load of $\sim 800 \mathrm{~N}$. The chosen deposition conditions lead to a growth rate of approximately $3 \mu \mathrm{m} \mathrm{h}^{-1}$ [15].

\subsection{Structural and tribological characterisations}

In this study, a variety of experimental techniques were used in order to assess diamond film quality, surface morphology and tribological response of the CVD diamond-coated $\mathrm{Si}_{3} \mathrm{~N}_{4}$ ceramics. The combination of measurements and diagnostic techniques was applied to correlate diamond grain size 
effect on the tribological performance of the diamond films. Ultrasonic cleaning of samples in ethanol was performed before each characterisation procedure.

Friction and wear testing of self-mated CVD diamondcoated $\mathrm{Si}_{3} \mathrm{~N}_{4}$ samples were conducted using an oscillating BOF adapted tribometer (PLINT TE67) in order to investigate the influence of diamond grain size on the tribological behaviour of this tribosystem. The diamond-coated balls (upper specimen) were fixed in a sample holder arm and made to contact with a defined load onto the diamond-coated flat square specimens mounted on a reciprocating table. The tests were performed under a dry sliding arrangement in open air $(\sim 50-60 \% \mathrm{RH})$ with a constant stroke and frequency of $6 \mathrm{~mm}$ and $1 \mathrm{~Hz}$, respectively. The duration of the tribological experiments were chosen to be $2 \mathrm{~h}$ for the regular tests, which corresponded to a sliding distance of approximately $86 \mathrm{~m}$. Endurance tests run for an uninterrupted period of time of $16 \mathrm{~h}$ (sliding distance, $x \sim 691 \mathrm{~m}$ ) were also performed for some selected contact forces. Static normal loads ranging from 10 to $105 \mathrm{~N}$ were applied directly over the ball specimens, by means of dead-weights. Assuming Hertzian theory for the elastic contact between a spherical/planar geometry, these conditions produced an initial contact pressure of approximately 5-11 GPa, respectively [16]. The friction force was measured by a load cell, its signal amplified and processed by a personal computer. Prior to testing, the load cell was calibrated by applying two to three known dead-weights in the range of the measured loads.

Micro-Raman spectroscopy was used to characterise the atomic bonding state and diamond film quality of the CVD coatings $[1,13]$. Further, measurements of the Raman diamond peak shift of worn CVD diamond films permitted residual stress state evaluation induced by the tribological action [5,17]. Micro-Raman measurements were carried out with a Jobin-Ybon spectrometer (Model T6400) using the $514.5 \mathrm{~nm}$ line of an argon-ion laser beam focused onto the film, with a spot size of $1 \mu \mathrm{m}$ and a laser power of few tens of $\mathrm{mW}$.

A Digital Instruments NanoScope IIIa atomic force microscope (AFM) was used to study the surface morphology of asgrown and worn CVD diamond films. Roughness values and surface features were calculated by inherent NanoScope III software. The surface microstructure, grain size and coating thickness of the studied CVD diamond films were observed by a Hitachi (model S-4100) scanning electron microscope. Furthermore, low amplification observations by SEM were also conducted with the purpose of measuring the radius of near circular wear scar of the ball specimens and thereby estimate the wear volume of this triboelement.

\section{Results and discussion}

\subsection{Morphology of as-grown and worn diamond films}

The initial diamond grain size and morphology of the three distinct coatings investigated in this work are shown
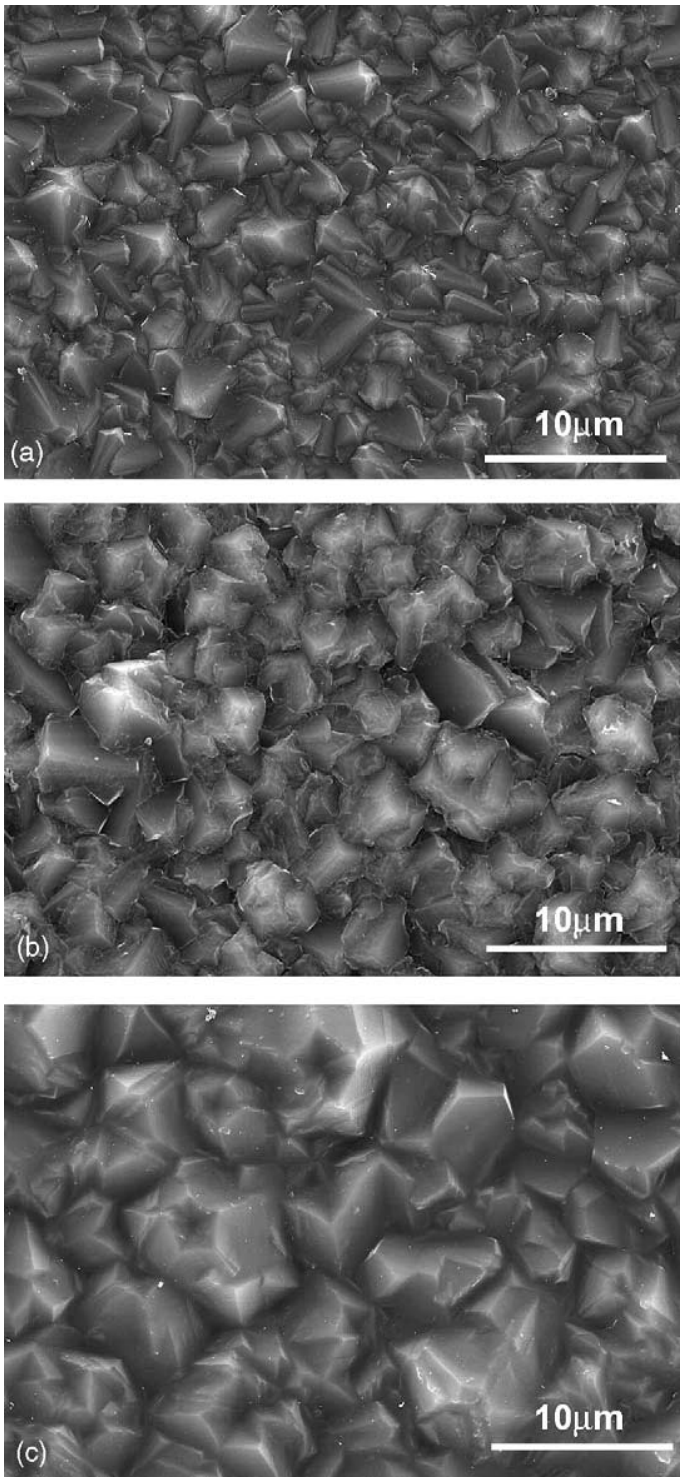

Fig. 1. SEM micrographs of CVD diamond coatings on $\mathrm{Si}_{3} \mathrm{~N}_{4}$ flat specimens: (a) $1 \mathrm{~h}$ of deposition time; (b) $2.5 \mathrm{~h}$; (c) $10 \mathrm{~h}$.

in Fig. 1. The polycrystalline films are composed of sharp, well-faceted micro-crystallites with diamond grain sizes of $1.8 \pm 0.8,2.4 \pm 1.1$ and $4.6 \pm 1.7 \mu \mathrm{m}$, for the $1,2.5$ and $10 \mathrm{~h}$ deposited coatings, respectively. The corresponding initial surface roughness $\left(R_{\mathrm{a}}\right)$ estimated from AFM characterization are 155,170 and $396 \mathrm{~nm}$ (load $=0 \mathrm{~N}$ in Fig. 2). Triangular $\left\{\begin{array}{lll}1 & 1 & 1\end{array}\right\}$ facets predominate in the larger grains. Such a surface morphology is characteristic of most conventional CVD-grown thin films $[9,17]$.

Selected AFM images of unworn and tribologically tested flat samples are presented in Fig. 3. Fig. 3a and b correspond to $1 \mathrm{~h}$ deposited specimens for the initial and the smoothest finishing condition, respectively. The latter one results from extensive self-polishing action against the coated sphere counterpart. A homologous pair but for the $2.5 \mathrm{~h}$ 


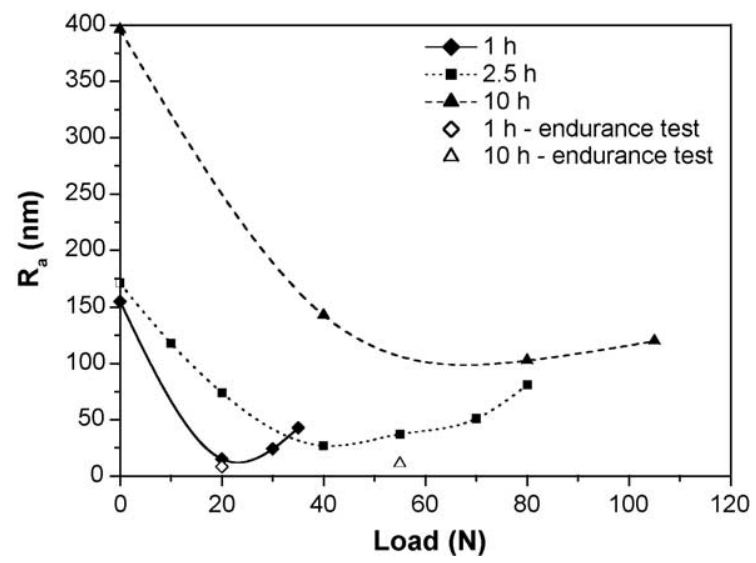

Fig. 2. Roughness average values as a function of applied load used in ballon-flat tribological experiments for distinct CVD deposition times (1, 2.5 and $10 \mathrm{~h}$ ). "Endurance tests" refer to $16 \mathrm{~h}$ sliding whereas the remaining results represent $2 \mathrm{~h}$ test runs.

diamond-coated material is depicted in Fig. $3 \mathrm{~d}$ and e. The images set in Fig. 4 correspond to the topographic features as a function of applied normal loads for the $10 \mathrm{~h}$ diamondcoated plate. The pictures show enhanced smoothening of the surface with increasing load, the diamond asperities being truncated as a result of the sliding process, as quantitatively revealed in Fig. 2. One of the features evidenced in Fig. 2 is the surface degradation above a specific load where a minimum of roughness takes place, namely for 1 and $2.5 \mathrm{~h}$ curves. This behaviour is supported by the image in Fig. 3c, where some evidence of what seems to be diamond pullouts are visible, i.e. micron-sized pits caused by localized removal of crystal aggregates. From Fig. 2, it is also clear that "endurance tests" of $16 \mathrm{~h}$ runs lead to similar finishing (very low $R_{\mathrm{a}}$ values of $8 \mathrm{~nm}$ ) independently of the initial diamond grain size. Similar surface morphologies for worn CVD diamond films were reported by a number of other works $[1,2,9,12]$.

The plots for each coating growth time given in Fig. 2, which are directly proportional to film thickness, also depict the respective critical loads $(35,80$ and $105 \mathrm{~N})$ prior to gross film detachment by delamination, therefore, leading to coating failure under tribological action. However, it is worth noting that a complete coverage of the diamond film on $\mathrm{Si}_{3} \mathrm{~N}_{4}$ substrate can still be observed after $16 \mathrm{~h}$ of sliding contact, even under $55 \mathrm{~N}$ of normal load, which suggest a strongly adhered coating to the substrate. Similar intense mechanical solicitation is not found in literature for tribological performance comparison.

\subsection{Bonding and stress state evolution induced by tribological action}

Raman spectroscopy is a suitable optical technique for analysing carbon-based materials, since it is able to give both chemical (non-diamond phases, dopants, impurities) and structural (strain) information [17]. The laser-optical Raman technique can differentiate with great precision the atomic bonding states of the carbon atoms $\left(\mathrm{sp}^{3}\right.$ for diamond and $\mathrm{sp}^{2}$ from other non-diamond forms of carbon such as graphite) due to their different vibrational modes [1].

Representative expanded micro-Raman spectra for a given sample (10 h deposited) are shown in Fig. 5a as a function of BOF applied load. For reference purposes, the Raman spectrum of the as-deposited film (untested) is also represented. Also, the curves were vertically displaced for viewing purposes. These curves are enlarged around the diamond peak
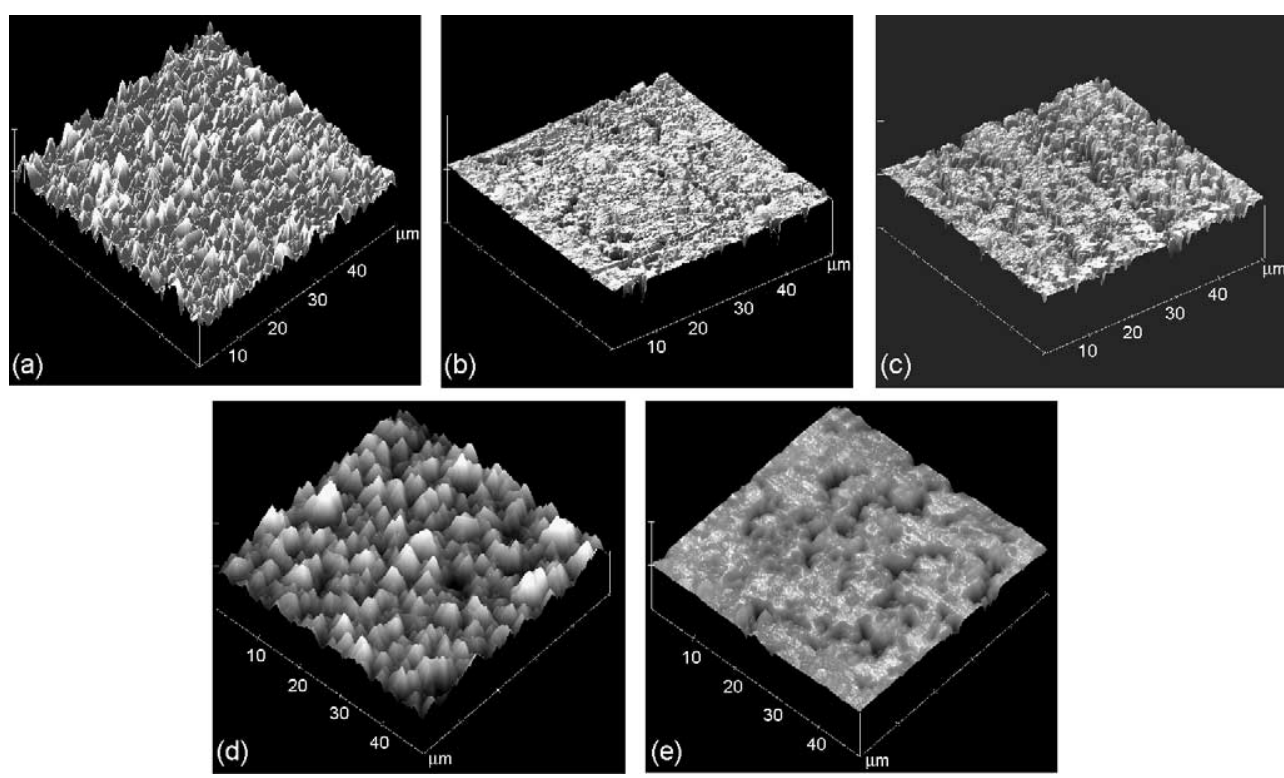

Fig. 3. AFM images of selected CVD diamond-coated $\mathrm{Si}_{3} \mathrm{~N}_{4}$ flat specimens: (a) $1 \mathrm{~h}$ deposited untested sample; (b) $1 \mathrm{~h}$ deposited and tested under $20 \mathrm{~N}$; (c) $1 \mathrm{~h}$ deposited and tested under $35 \mathrm{~N}$; (d) $2.5 \mathrm{~h}$ deposited untested sample; (e) $2.5 \mathrm{~h}$ deposited and tested under $40 \mathrm{~N}$. 

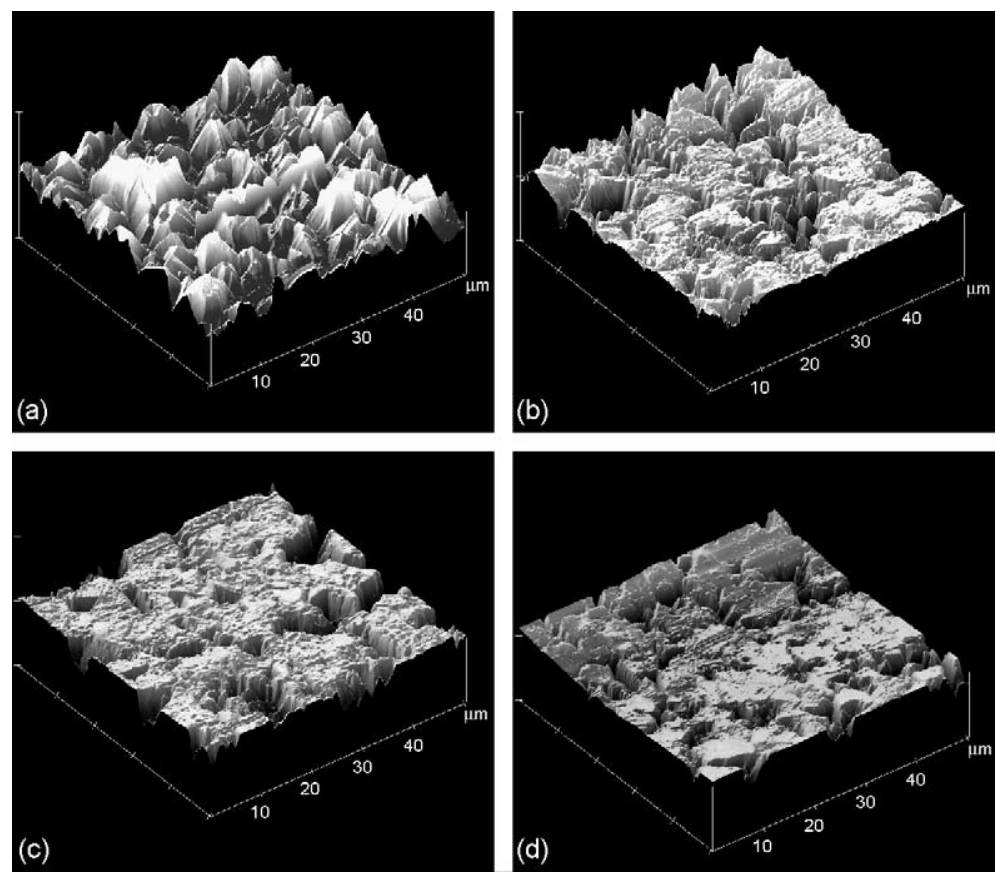

Fig. 4. AFM pictures showing the variation of topographic features with applied loads for the $10 \mathrm{~h}$ grown CVD diamond coatings: as-deposited (a); after $40 \mathrm{~N}$ (b); $80 \mathrm{~N}$ (c); $105 \mathrm{~N}$ (d) sliding.

$\left(1332 \mathrm{~cm}^{-1}\right)$ with the purpose of evidencing diamond peak shifts and associated residual stress state of each film. The picture shows a positive shift of the diamond peak with increasing loads as well as FWHM broadening resulting from enhanced compressive state and anisotropic stress distribution resulting from the contact pressures arising during the sliding tests [17]. The same trend is observed for increasing sliding distances, at constant load, as depicted in Fig. 5b. Full spectra do not show any signs of graphitic phases even after tribological action (see Fig. 5c).

Several groups have used Raman spectroscopy for stress measurements in diamond films. The dependence of the diamond Raman line shift on applied pressure can be estimated from the expression $\sigma \sim-0.345 \Delta \nu \mathrm{GPa} \mathrm{cm}^{-1}$, where $\Delta v$ represents the shift of the diamond line [5]. An upward or downward shift will indicate a compressive or tensile stress state for the diamond film, respectively. Results from residual stress calculations are plotted in Fig. 5d. All studied films have revealed a compressive nature, which is less accentuated for the thicker coatings grown for $10 \mathrm{~h}$ due to a better in-depth accommodation of the contact pressure. The increment of the peak shift with load already seen in Fig. 5a reflects itself in the positive slope of the compressive residual stress versus load plot, Fig. 5d.

\subsection{Friction and wear properties of diamond films}

Typical friction curves obtained for the sliding tests of the self-mated CVD diamond-coated $\mathrm{Si}_{3} \mathrm{~N}_{4}$ materials are characterized by an initial ephemeral sharp peak followed by a gradual decay of the coefficient of friction to very low steadystate values $(\mu \sim 0.03)$. To illustrate the friction regimes occurring in the sliding tests, a detail of an overall instantaneous friction curve is shown in Fig. 6a. Identified in each plot are three distinct regimes (labelled I, II and III) that correspond to a different behaviour for the friction coefficient. Regime I is the initial transient resulting from intense mechanical interactions between the sharp tips of diamond asperities of both the contacting surfaces. As sliding continued and the ball passed repeatedly over the same track, the coefficient of friction is significantly affected by the gradual blunting of asperities tips. Regime II corresponds to a relatively short transition stage and it is the result of the runningin effect of accommodation between counter-bodies and debris action. Afterwards, and for the rest of the duration of the tests, the coefficient of friction levelled off and tended to stabilise (Regime III). Likewise, after the coefficient of friction has reached its steady-state value it remained stable for the full duration of the tests, even for the endurance tests (sliding distance $x \sim 691 \mathrm{~m}$ ). This behaviour for the stationary friction coefficient is in accordance with data from other authors $[1,12]$ for the dry sliding of diamond films in humid air, being a consequence of the resulting smooth passivated contacting surfaces and low final Hertzian contact pressures.

The variation curves for the initial maximum friction coefficient $\left(\mu_{\max }\right)$ with applied normal load are presented in Fig. 6b. As expected, $\mu_{\max }$ shows a growing tendency with increasing load as a result of the higher initial maximum contact pressures at stake that in turn gave rise to bigger friction 

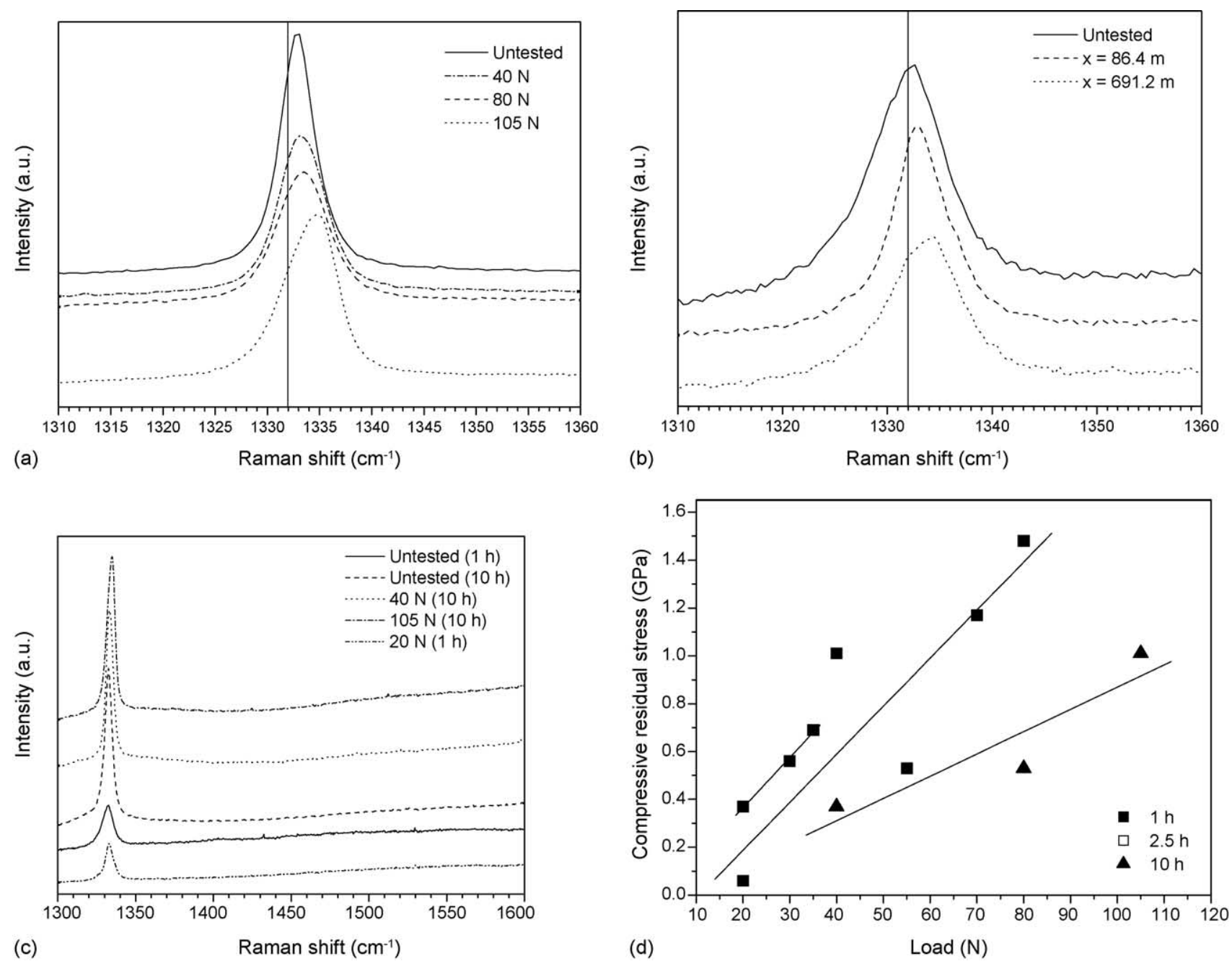

Fig. 5. Micro-Raman spectra around the diamond peak $\left(1332 \mathrm{~cm}^{-1}\right)$ : (a) curves for untested and worn samples of the $10 \mathrm{~h}$ grown CVD diamond flat specimens for different applied normal loads; (b) curves for untested and worn samples of the $1 \mathrm{~h}$ grown CVD diamond flat specimens for different sliding distances under $20 \mathrm{~N}$; (c) extended spectra including the graphite band region for untested and worn samples of 1 and $10 \mathrm{~h}$ grown CVD diamond flat specimens for different applied normal loads; (d) calculated compressive residual stresses induced by tribological action plotted as a function of applied load for different films.

forces. Likewise, a direct dependence of $\mu_{\max }$ on the initial surface roughness of the film is observed [1].

The wear coefficient of the ball specimens $\left(K_{\mathrm{b}}\right)$ were calculated from the diameter of the near circular wear scars observed after completion of the tests. That is, in cases that wear can be neglected on the flat specimen, i.e. only wear of the ball is considered on a BOF tribosystem, the volumetric wear $(V)$ can be calculated from the diameter $(d)$ of the scar and the radius ( $r$ ) of the ball according to: $V=\pi d^{4} / 64 r$ [18]. Fig. 7 shows the calculated values of $K_{\mathrm{b}}$ for the distinct films after $2 \mathrm{~h}$ sliding tests. The wear coefficient values were calculated in accordance with Archard's law: $K_{\mathrm{b}}=V / x W$, where $x$ is the sliding distance and $W$ is the applied load. Wear coefficients in the $10^{-7} \mathrm{~mm}^{3} \mathrm{~N}^{-1} \mathrm{~m}^{-1}$ order of magnitude denote a mild wear mode for the self-mated CVD diamond films sliding in ambient air. It is noteworthy that the assessed values for the endurance tests show values one order of magnitude smaller, i.e. in the ultra-mild wear mode range. As can be seen from
Fig. 7, the wear coefficients are slightly dependent on grain size, or initial surface roughness, of the CVD diamond films.

Miyoshi [3] found wear coefficients in the $1.0 \times 10^{-7}$ to $1.2 \times 10^{-7} \mathrm{~mm}^{3} \mathrm{~N}^{-1} \mathrm{~m}^{-1}$ range for coarse grain $(3.3 \mu \mathrm{m})$ diamond films, similar to the present ones. However, the tribosystem used consisted of a natural single-crystal diamond pin sliding over a CVD diamond-coated $\alpha-\mathrm{SiC}$ substrate, in humid air (RH of $40 \%$ ). In other work by Miyoshi et al. [13], observed wear rates in the $2 \times 10^{-6}$ to $3 \times 10^{-6} \mathrm{~mm}^{3} \mathrm{~N}^{-1} \mathrm{~m}^{-1}$ range are reported for a CVD diamond pin sliding over a polished diamond film in humid air (RH of $40 \%$ ) and an applied load of just $0.98 \mathrm{~N}$. Considering the widely differing roughness and experimental geometries involved, the wear rates shown in the present study are consistent with those of the diamond on diamond experiments previously referred, if not better. Further, higher applied loads have been used in the present work. This suggests that CVD diamond-coated $\mathrm{Si}_{3} \mathrm{~N}_{4}$ films have compara- 

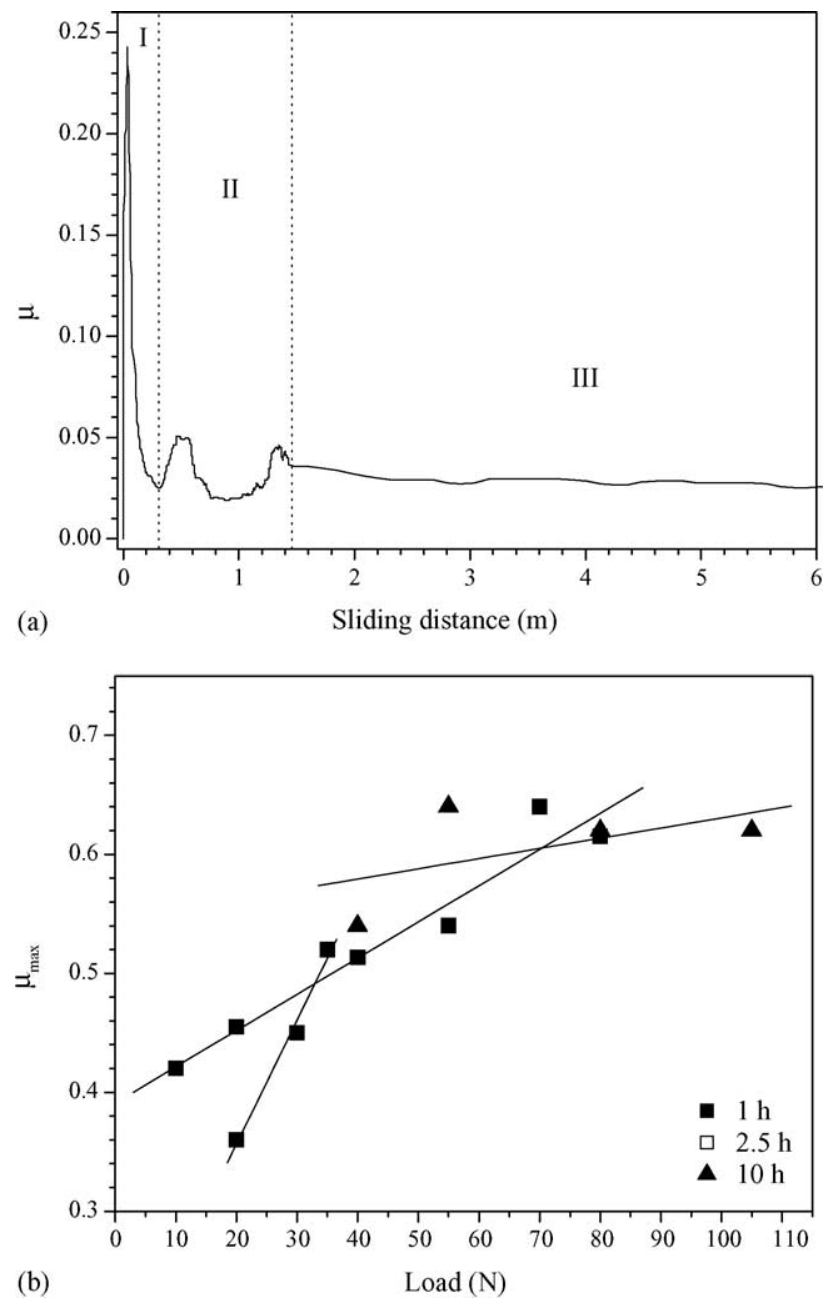

Fig. 6. (a) Representative curve of the friction coefficient evolution showing distinct friction regimes ( $1 \mathrm{~h}$ deposited film tested under $20 \mathrm{~N})$. (b) Variation of the initial friction coefficient $\left(\mu_{\max }\right)$ with applied normal load for the three kind of CVD coatings.

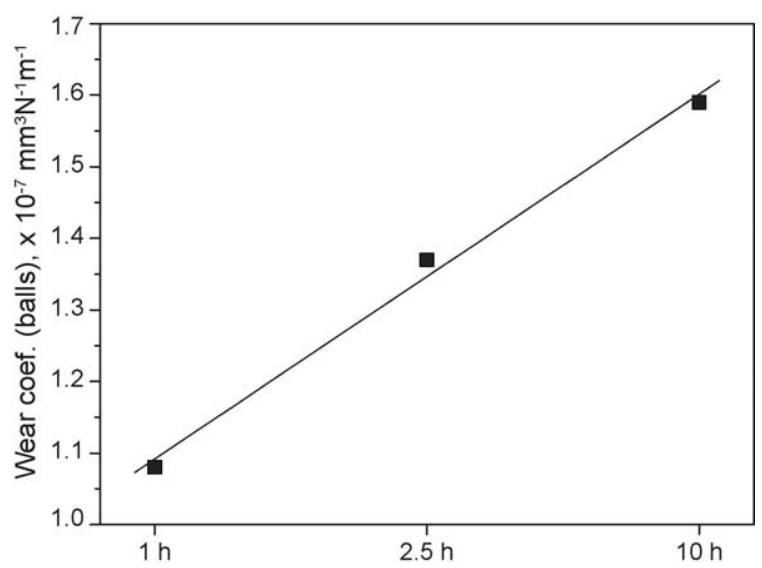

Fig. 7. Average ball wear coefficient values for self-mated tribological tests with distinct deposition time CVD diamond films. ble wear resistances to single-crystal diamonds, despite their polycrystalline morphology and associated grain boundaries.

\section{Conclusions}

Continuous, well-adhered CVD diamond on silicon nitride flat and ball specimens were produced by microwave plasma technique. Self-mated ball-on-flat tribological dry tests reveal a self-polishing mechanism accomplished by diamond asperities truncation. This lead to very low surface roughness finishing of approximately $8 \mathrm{~nm}$ after $16 \mathrm{~h}$ sliding runs. Such extremely low values occur at a specific applied load above which some surface degradation takes place by diamond pull-outs. The finishing quality is improved for the lower grain sized coatings $(1.8 \mu \mathrm{m})$ but these fail at much lower loads $(35 \mathrm{~N})$ than the larger grain sized $(4.6 \mu \mathrm{m})$ and thicker ones that delaminate only at $105 \mathrm{~N}$.

Micro-Raman characterisation of the tested samples did not reveal any signs of surface graphitic phase transformation. Spectra show increasingly diamond peak broadening and positive shift deviation with increasing loads, or increasing sliding distances, coming from higher compressive residual stresses and enhanced stress anisotropy imposed by the contact pressures, or working time. The compressive magnitude of the residual stresses is smaller for the thicker coatings grown for $10 \mathrm{~h}$, with values below $1 \mathrm{GPa}$, due to a better indepth accommodation of the contact pressure.

The friction evolution of the self-mated tests with the CVD diamond-coated $\mathrm{Si}_{3} \mathrm{~N}_{4}$ materials starts with a sharp peak arising from mechanical interlocking between the diamond asperities. A subsequent transition regime of runningin, corresponding to the accommodation between counterbodies, leads to a final steady-state regime where very low friction values $(\mu \sim 0.03)$ are attained. In this regime, the wear coefficient of the balls reached a value of the order of $10^{-8} \mathrm{~mm}^{3} \mathrm{~N}^{-1} \mathrm{~m}^{-1}$, denoting a mild wear mode.

\section{Acknowledgements}

C.S. Abreu acknowledges PRODEP III funds supporting his $\mathrm{PhD}$ work. The financial funding from the FCT Project POCTI/CTM/45423/2002 is also gratefully acknowledged.

\section{References}

[1] K. Miyoshi, R.L.C. Wu, Measurements and diagnostics of diamond films and coatings, Measurement 29 (2001) 113-126.

[2] M.N. Gardos, Tribological fundamentals of polycrystalline diamond films, Surf. Coat. Technol. 113 (1999) 183-200.

[3] K. Miyoshi, Friction and wear properties of as-deposited and carbon ion-implanted diamond films, Mater. Sci. Eng. A 209 (1996) 38-53.

[4] S.A. Catledge, Y.K. Vohra, Mechanical properties and quality of diamond films synthesized on Ti-6Al-4V alloy using the microwave plasmas of $\mathrm{CH}_{4} / \mathrm{H}_{2}$ and $\mathrm{CO} / \mathrm{H}_{2}$ systems, J. Appl. Phys. 83 (1998) 198-204. 
[5] N.G. Ferreira, E. Abramof, N.F. Leite, E.J. Corat, V.J. Trava-Airoldi, Analysis of residual stress in diamond films by X-ray diffraction and micro-Raman spectroscopy, J. Appl. Phys. 91 (2002) 24662472.

[6] G.A. Jones, On the tribological behaviour of mechanical seal face materials in dry line contact. Part II. Bulk ceramics, diamond and diamond-like carbon films, Wear 256 (2004) 433-455.

[7] A. Erdemir, G.R. Fenske, A.R. Krauss, D.M. Gruen, T. McCauley, R.T. Csencsits, Tribological properties of nanocrystalline diamond films, Surf. Coat. Technol. 120-121 (1999) 565-572.

[8] M. Belmonte, A.J.S. Fernandes, F.M. Costa, F.J. Oliveira, R.F. Silva, Adhesion behaviour assessment on diamond coated silicon nitride by acoustic emission, Diamond Relat. Mater. 12 (2003) 733-737.

[9] K. Mallika, R. Komanduri, Low pressure microwave plasma assisted chemical vapour deposition (MPCVD) of diamond coatings on silicon nitride cutting tools, Thin Solid Films 396 (2001) 145-165.

[10] I.P. Hayward, I.L. Singer, L.E. Seitzman, Effect of roughness on the friction of diamond on CVD diamond coatings, Wear 157 (1992) 215-227.

[11] S.E. Grillo, J.E. Field, The friction of natural and CVD diamond, Wear 254 (2003) 945-949.
[12] C. Met, L. Vandenbulcke, M.C. Sainte Catherine, Friction and wear characteristics of various prosthetic materials sliding against smooth diamond coated titanium alloy, Wear 256 (2003) 1022-1029.

[13] K. Miyoshi, M. Murakawa, S. Watanabe, S. Takeuchi, S. Miyake, R.L.C. Wu, CVD diamond, DLC, and c-BN coatings for solid film lubrication, Tribology Lett. 5 (1998) 123-129.

[14] M. Belmonte, V.A. Silva, A.J. Fernandes, F. Costa, R.F. Silva, Surface pretreatments of silicon nitride for CVD diamond deposition, J. Am. Ceram. Soc. 86 (2003) 749-754.

[15] M.R. Soares, M. Belmonte, R.F. Silva, Low incident angle and classical X-ray diffraction analysis of residual stresses in diamond coated $\mathrm{Si}_{3} \mathrm{~N}_{4}$, J. Appl. Phys. 94 (2003) 5633-5638.

[16] P.D. Warren, Determining the fracture toughness of brittle materials by Hertzian indentation, J. Euro. Ceram. Soc. 15 (1995) 385-394.

[17] M. Mermoux, B. Marcus, L. Abello, N. Rosman, G. Lucazeau, In situ Raman monitoring of the growth of CVD diamond films, J. Raman Spectrosc. 34 (2003) 505-514.

[18] E. Zeiler, D. Klaffke, K. Hiltner, T. Grogler, S.M. Rosiwal, R.F. Singer, Tribological performance of mechanically lapped chemical vapor deposited diamond coatings, Surf. Coat. Technol. 116-119 (1999) 599-608. 